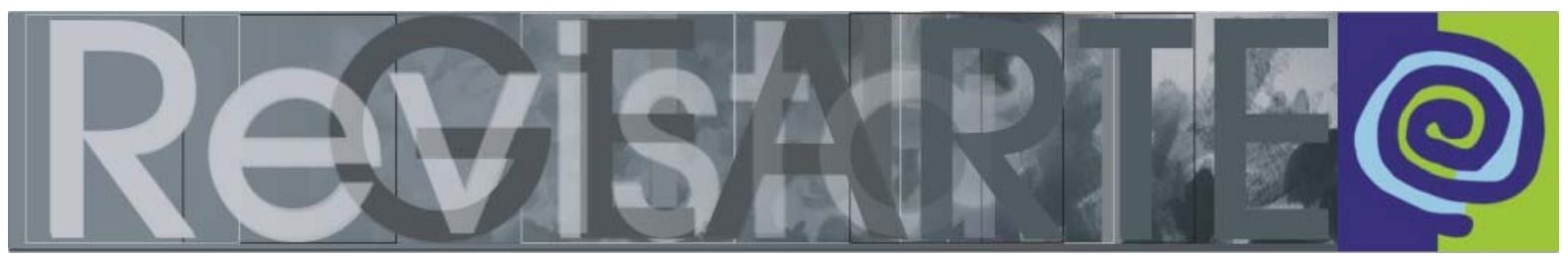

ISSN 2357-9854

\title{
Produção de sentido: imagem, arte e mistura de corpos
}

\author{
Alberto Coelho (IFSUL - Brasil)
}

\begin{abstract}
RESUMO
Este artigo propõe como foco temático um estudo teórico sobre produção de sentido e imagem, articulando as relações artista e espectador / professor de arte e aluno. A imagem está presente em nosso cotidiano, mas ainda permanece a questão sobre o que sabemos dela e "como" ela pensa as condições de uma vida digital em desenvolvimento. Pergunta-se sobre 0 funcionamento do sentido em propostas artísticas e em práticas pedagógicas, atento aos pontos de conexão entre essas experiências. Segue-se a seguinte metodologia: apresenta-se a imagem na contemporaneidade, depois o conceito de sentido presente na obra "Lógica do Sentido" de Gilles Deleuze, a fim de encaminhar um estudo sobre situações que promovem o sentido como produção de atos de criação com a imagem e a arte. O artigo tem como objetivo problematizar a produção de sentido com arte como mistura de corpos, cujos efeitos causam acontecimentos.
\end{abstract}

PALAVRAS-CHAVE

Produção de sentido. Corpo. Arte. Espectador.

\section{RESUMEN}

Este artículo propone como enfoque temático un estudio teórico sobre la producción de sentido y la imagen, articulando artista y espectador / profesor de arte y alumno. La imagen está presente en nuestro cotidiano, pero aun así, permanece la cuestión de lo que sabemos de ella, y cómo ella piensa las condiciones de una vida digital en desenvolvimiento. Se pregunta sobre el funcionamiento del sentido en propuestas artísticas y prácticas pedagógicas, atentos a los puntos de conexión. De ello se desprende la siguiente metodología: se presenta la imagen en la contemporaneidad, después el concepto del sentido de la obra "Lógica del sentido" de Gilles Deleuze, con el fin de encaminar un estudio sobre situaciones que promueven el sentido como producción de actos de creación con la imagen y el arte. El artículo tiene como objetivo problematizar la producción de sentido con arte como una mezcla de cuerpos cuyos efectos causan acontecimientos.

PALABRAS CLAVE

Producción de sentido. Cuerpo. Arte. Espectador.

Os desdobramentos de minha tese, desenvolvida no curso de doutorado em Artes Visuais, ênfase em História, Teoria e Crítica de Arte, pela Universidade Federal do Rio Grande do Sul (UFRGS), quando enfoquei minhas experiências estéticas com arte e Instalações Interativas Computacionais (IIC) ${ }^{1}$, ocorreram

\footnotetext{
1 A pesquisa, defendida em 2009, aborda minhas experiências estéticas com Instalações Interativas Computacionais (IIC). A ideia é produzir um pensamento sobre o funcionamento da interatividade com interfaces digitais em mundos virtuais produzidos como arte, na perspectiva de fundamentar exercícios de uma contemplação interfaceada de sensações, processados por um corpo-interator a partir de sua interação com o entorno. Coloca-se em trabalho o conceito de contemplação estética, encaminhando uma abordagem que permita compreender sua compatibilidade com as tecnologias digitais, longe da dicotomia ativo $\mathrm{x}$ passivo e, fundamentada
} 
mediante uma nova apropriação dos resultados, dos objetivos investigativos e do aporte teórico. Neste redimensionamento a experiência com imagem se evidenciou como possibilidade de continuação quando do meu retorno ao campus Pelotas do Instituto Federal Sul-rio-grandense (IFSUL), onde exerço minha docência em arte $^{2}$, e onde o material da tese passou a ser submetido às questões que se referem à área de Educação (Ensino e Pesquisa).

Antes de minha saída para o doutorado, os cursos de ensino médio integrado especificavam conteúdos de Artes Visuais, para os quais eram preparadas atividades que envolviam dados históricos (títulos de obras, técnicas, principais artistas...), apreciação e crítica de arte, dentre outras demandas que um planejamento de curso exige ${ }^{3}$. Quando retornei ao trabalho, em 2009, minha atuação docente se estendeu aos cursos de Graduação, Especialização e Mestrado, nestes segmentos, empenhado com questões especificas sobre imagem e imagem digital, passei a trabalhar com todo um universo caracterizado e traduzido pelo bit $^{4}$. A pesquisa de doutorado, iniciada em 2005 , conferiu um referencial tecnológico que colocou a imagem digital como protagonista, proporcionando intensas aprendizagens a respeito da arte, do corpo e dos ambientes instalados pelo computador.

No andamento das atividades, meu repertório imagético, que já ocupava um espaço importante no trabalho de pesquisador e professor de arte, foi se compondo com imagens de outras áreas — Publicidade, Design, Música (Videoclipes), Internet, Cinema (Animação), trazendo imagens contaminadas

no conceito de arte como um bloco de sensações, composto de afectos e perceptos. A hipótese principal funda-se na noção de contemplação como contração de sensações, segundo Gilles Deleuze e Felix Guattari, autores que compõem as filosofias da diferença.

2 Atuo como professor nos cursos de Ensino Médio Integrado, Graduação (Bacharelado em Design), Especialização (em Educação e em Linguagens Verbais e Visuais) e Mestrado (em Educação e Tecnologia). Trabalho com Pesquisa, desenvolvendo projetos de Iniciação Cientifica e com o grupo "Educação e contemporaneidade: experimentações com arte e filosofia, EXPERIMENTA".

${ }^{3}$ Até aquele momento trabalhava só com turmas de Ensino Médio, quando voltei em 2009 já estavam em funcionamento os cursos de Graduação e Pós-graduação.

${ }^{4}$ Bit, impulso elétrico da linguagem computacional, é a menor unidade de informação que pode ser armazenada ou transmitida. Um bit possui dois valores, 0 ou 1, é corte ou é passagem de energia respectivamente. 
pelo pixel, pelo numérico. Foi neste mesmo período, e com o mesmo interesse, que dei início às minhas pesquisas $\mathrm{PIBIC}^{5}$.

Do ano de 2010 até 2012, ministrei no curso de Pós-Graduação em Linguagens Verbais e Visuais e suas Tecnologias ${ }^{6}$, duas disciplinas: "Produção de imagem e sentido" e "Imagem digital, arte e subjetivação". Perguntava: quais pressupostos conceituais poderiam fundamentar a expressão produção de sentido? Como funcionaria esta produção quando se tratava de imagem digital e obra de arte visual? Eu documentava os encontros, principalmente a experiência de meus alunos, em especial com imagens da arte, com anotações diárias que acabaram por estimular escritas e publicações de minhas práticas.

O aporte teórico filosófico que me auxiliou a buscar respostas para as questões constituiu-se de alguns conceitos criados pelas filosofias da diferença, em especial pelo filósofo Gilles Deleuze. Eles atendiam minhas necessidades quanto a fundamentar as experiências com imagens em como tudo estava implicado com os modos de viver e pensar o mundo contemporâneo, em seu devir.

\footnotetext{
${ }^{5}$ Devido ao meu afastamento para o pós-doc desenvolvi até agosto de 2014 dois projetos de pesquisa PIBIC: $\left.1^{\circ}\right)$ A imagem na formação docente e a noção de subjetividade digital (2010, 2011 e 2012) projeto que tratou da interação com imagens digitais, de meus alunos e dos docentes e alunos do IFSUL, campus Pelotas, fundamentando a noção de subjetividade digital, movimento de bits, átomos e afecções/percepções que altera nossos hábitos e modos de viver no mundo contemporâneo. Dentre os objetivos estavam: investigar a produção de sentido de alunos e professores, a partir de dispositivos de visualização e de montagem de imagens digitais e, propor produções escritas sobre experiências com Web arte, videoclipes, animação digital e sites. $2^{\circ}$ ) Aprendendo: intervenções e produção de saberes sensíveis no campus Pelotas (2013), projeto que problematizou o ritmo diário de uma instituição de educação, ciência e tecnologia tradicional como é o campus Pelotas, quando interceptada por intervenções artísticas, projeções montadas em lugares de circulação. As projeções pensadas - práticas artísticas que envolviam vídeos - buscaram favorecer experiências estéticas provocadoras de estranhamentos. Os objetivos delimitados eram: propor momentos para que novos afetos, novos modos de subjetivação fossem provocados no cotidiano do instituto e, identificar a relação dos docentes com as projeções, quanto a uma disponibilidade e abertura para situações inusitadas, considerando a tradição técnica vivida no campus.

${ }^{6} \mathrm{O}$ curso de Pós-Graduação em Linguagens Verbais e Visuais e suas Tecnologias, em nível de Especialização, visa proporcionar a capacitação e/ou atualização de professores, principalmente da área de Linguagens, Códigos e suas Tecnologias, da Rede Pública de Ensino, através do estabelecimento de um fórum constante de debate, em que sejam contempladas análises e reflexões acerca do papel exercido pela linguagem em contextos verbais e visuais e seus complexos sistemas de representação, seus estatutos e processos de produção e recepção, que se atualizam em múltiplos espaços de forma relacional.
} 
Nos exercícios de produção de sentido propostos para meus alunos, buscava alcançar uma abordagem que conseguisse fundir educação e modos de subjetivação, atenuando a linha que separa educação formalizada e vida. Mapeava os exercícios realizados pelos alunos, utilizando recursos, tais como: questionários, entrevistas, fotografias, vídeos, e, também, ensaios, escritas curtas, anotações aleatórias e boas conversas.

\section{Imagem [digital] no mundo contemporâneo.}

Com a década de 1990 vivemos o começo da popularização da Internet, tempo de uma subjetividade digital se instalando, definindo-se como um conjunto de acontecimentos gerado pela presença das Tecnologias de Informação e Comunicação (TIC), algo que parece mais relacionado com pessoas do que com computadores. Comunicação informatizada, bits se dissipando à velocidade da luz. Esta subjetividade contemporânea, condicionada a interfaces de capturas, visualizações, manipulações e imersões, encontra na imagem digital sua mais forte componente.

A imagem torna-se o foco de muitos interesses; proliferam-se estudos e publicações em diferentes áreas. Já pertence ao senso comum uma espécie de onipresença da imagem, pois realmente podemos encontrá-la por todos os lugares. Jacques Aumont (2012, p. 8) fala que a expressão "civilização da imagem", "revela bem o sentimento generalizado de se viver em um mundo onde as imagens são cada vez mais numerosas, mas também cada vez mais diversificadas e mais intercambiáveis". É impossível negar que a responsabilidade por trazer as imagens tão próximas a nós, tornando-as companheiras de nosso dia a dia, pertence em grande parte às tecnologias digitais.

Chama-nos a atenção os televisores fixados nas paredes de muitos estabelecimentos, como bares, restaurantes, clínicas de exames, repartições públicas. O celular, antes um artigo somente para comunicação, se tornou um dispositivo que nos permite fotografar a qualquer momento; podemos receber e enviar muitas imagens, instantaneamente. Para alguns as máquinas fotográficas já se encontram esquecidas nas gavetas de seus armários e criados-mudos. 
Mas, embora a imagem esteja presente cotidianamente, ao ponto de ser um artigo banalizado, ainda permanece a questão sobre o que sabemos dela e "como" ela pensa a realidade, o momento presente, as condições de uma vida digital em desenvolvimento. Ethiene Saman (2012, p. 22), ao tentar um esclarecimento sobre a imagem diz: "toda imagem [...] nos oferece algo para pensar: ora um pedaço de real para roer, ora uma faísca de imaginário para sonhar". Para o autor, antes de saber o porquê ela nos faz pensar, ele nos convoca primeiro saber "como" ela nos faz pensar.

Em busca deste "como", pela observação dos produtos de uma cultura digital, hipertextual, multissensorial, utilizo um aporte teórico que fundamenta e estimula produções de sentido com imagens, em especial as digitais. Meu percurso se faz por uma leitura atenta às filosofias da diferença. Escolher a obra Lógica do Sentido, utilizando-a como referencial me parece bastante apropriado. É assim que levo adiante esta caminhada, como poderemos ver a seguir.

\section{O sentido e as dimensões da proposição em Gilles Deleuze}

Acompanho-me do filósofo Gilles Deleuze (1998) e sua obra Lógica do Sentido, escrita em 1969, na qual ele procura estabelecer, a partir da obra de Lewis Carroll, autor de "Alice no país das maravilhas" (1865) e "Alice no país dos espelhos" (1871), uma teoria para o sentido utilizando como termo de elucidação o pensamento dos estóicos. Estes filósofos do pórtico (stoa) têm o paradoxo "ao mesmo tempo como instrumento de análise para a linguagem e como meio de síntese para os acontecimentos" (DELEUZE, 1998, p. 9). Lógica do Sentido se compõe de um apêndice com cinco artigos e uma série de 34 paradoxos com os quais se formam a teoria do sentido. Algumas de suas indicações tratam da primeira questão do artigo, sobre os pressupostos conceituais que fundamentam a expressão produção de sentido. Para tanto encaminho uma pequena introdução ao tema, elegendo a "Terceira Série: Da Proposição" (DELEUZE, 1998, p. 13), certo de que não darei conta da complexidade da obra, mas satisfeito quanto a atender o objetivo proposto. Vale comentar que ler Lógica do Sentido pressupõe uma tarefa que não se encerra em algumas leituras do livro, mas em várias, sendo necessárias muitas paradas, anotações, 
questionamentos, retorno ao início, para que a teoria do sentido não perca sua forma paradoxal.

É importante ressaltar que esta é uma apropriação que não busca reverter seus dados para um "modelo de leitura de imagem". A obra Lógica do Sentido como subsídio conceitual e pragmático, nos orienta na busca por saber acerca do funcionamento da produção de sentido, quando se encontram sujeito, arte, imagem ou outros tantos corpos em mistura. Assim, qualquer tentativa de sistematização da "teoria do sentido" de Deleuze, traduzindo possíveis estágios para o desenvolvimento de uma experiência com imagem, aborta a sua possibilidade de fundamentar a experiência quanto a agenciamentos (DELEUZE, 1998a, p. 65), cujos efeitos causam acontecimentos que estão em relação a incorporais, a forças e intensidades que escapam a qualquer modelo mensurável, e que não podem ser organizadas por percursos lineares.

Parto do termo produção opondo-o à ideia de coleta de dados, ou ao que estaria em relação a uma experiência discursiva, relacionada à noção de interpretação, a qual pressupõe a decifração de um dado a priori, que vê a imagem apenas como semelhança, uma cópia do real e que, portanto, é possuidora de uma mensagem ou significado. Presente numa imagem tal enigma corresponderia às essências que pairam no mundo das ideias, mundo platônico inteligível, mundo modelo, que aguarda ser adivinhado no final de um processo linear, como uma descoberta realizada por quem vê com aquele olhar de quem espera encontrar ou confirmar uma verdade.

Na "Terceira Série: Da Proposição", Deleuze entende que o sentido é a quarta dimensão da proposição, e está junto a designação, a manifestação e a significação. Mas o que é uma proposição? Uma proposição é aquilo que expressa o possível de um acontecimento. E é próprio dos acontecimentos serem exprimíveis, enunciados ou enunciáveis. O sentido, então, se produz no encontro de corpos e ideias, e se efetua através da linguagem. A linguagem é o que se diz das coisas e com a qual dizemos do sentido produzido através de proposições. O "sentido é o expresso da proposição, este incorporal na superfície das coisas, entidade complexa irredutível, acontecimento puro que 
insiste ou subsiste na proposição" (DELEUZE, 1998b, p.20). Tudo ocorre na articulação entre o significante e o significado. Numa explicação muito breve: a série das designações é a série do significante (nomes e coisas) e a série das expressões é a série dos significados (verbos e expressões).

Daquilo que expressa o possível de um acontecimento, a proposição, Deleuze destaca outras três relações, a saber: as designações, as manifestações e as significações. E, não será possível reconhecer o sentido em nenhuma delas devido a algumas limitações que não lhes permitem funcionar $a$ priori.

A designação ou indicação é a relação da proposição a um estado de coisas exteriores. A "designação opera pela associação das próprias palavras com imagens particulares que devem 'representar' o estado de coisas" (DELEUZE, 1998b, p. 13), estado que é individual e que comporta relações. Designações comportam misturas de corpos - relações, quantidades e qualidades. Para Deleuze, o que há nos corpos, na profundidade dos corpos, são misturas: um corpo penetra no outro e coexiste com ele em todas as suas partes, como a gota de vinho no mar ou o fogo no ferro" (1998b, p. 06). Porém, os corpos são causa de alguma coisa que deles difere em natureza, o que, para os estóicos se chama incorporais. Ser '“algo' é, portanto, o único aspecto comum entre os corpos e os incorporais" (PIZARRO, s/ d, p. 37). Resultam das misturas dos corpos os acontecimentos incorporais, estes não têm existência espaçotemporal presentificada como os corpos, eles são "algo" - alguma coisa, algo mais.

As designações têm como critério o verdadeiro e o falso. Designar é associar uma palavra que venha a representar uma imagem. Por isso, o sentido não pode ser encontrado aí; e, não se pode dizer verdadeiro ou falso do sentido de uma proposição.

A manifestação é a segunda relação da proposição, esta trata do sujeito que fala e que se exprime. O "Eu" é o manifestante privilegiado, manifestante de base. Domínio do pessoal, esse Eu depende dos outros manifestantes, mas não só deles. A "manifestação se apresenta, pois como o enunciado dos desejos e 
das crenças que correspondem à proposição" (DELEUZE, 1998b, p. 14). As manifestações correspondem aos desejos e crenças, e são inferências causais e não associações de um sujeito. É a manifestação que torna possível uma designação.

A significação seria uma terceira dimensão da proposição, "trata-se desta vez da relação da palavra com conceitos universais e gerais, e das ligações sintáticas com implicações de conceitos" (DELEUZE, 1974, p. 15). Aqui temos os elementos da proposição como significantes que possuem a capacidade de remeter a outras proposições, expressões dos possíveis que um acontecimento provoca.

Quando se busca entender a produção de sentido a partir desta abordagem, intervêm neste estado de coisas, também a fala, a língua e o nonsense (o sem-sentido), elementos que pedem um tratamento conceitual mais demorado o qual, por questões de tempo e espaço, não se pode ofertar neste artigo, ficando como possibilidade para outra ocasião.

\section{O artista e o espectador I o professor e o aluno: o sentido como produção de atos de criação}

O sentido fundamentado em Deleuze alcança o artista, ao fazer sua obra, e o espectador, ao apreciar, participar, interagir com ela; também o professor, que prepara uma aula e o aluno que recebe, sente e percebe esta aula. Apesar de serem quatro modos distintos de produzir, eles se assemelham em algum nó na sua forma propositora quando a questão central é a produção de atos de criação na mistura de corpos.

Quanto à prática do artista, a produção de sentido fica por conta de uma captura de forças em um plano de composição. Neste caso a tarefa do artista não consiste em "coletar dados", o que ele faz tem a ver com processos criadores que buscam produzir compostos de afectos e perceptos (DELEUZE ; GUATTARI, 1992, p. 272) seres incorporais que excedem qualquer vivido. O artista se torna produtor na medida em que agencia seus materiais de trabalho a um regime de signos, realizando correspondências e acoplamentos por entre 
os corpos. Forças capturadas entram em uma produção inventiva, estas encontram na visualidade, ou na sonoridade ou tatilidade do plano técnico, modos de instauração. Novas afecções poderão ser possibilitadas por essas peças de arte, proposições formalizadas pelos recursos materiais e estéticos utilizados pelo artista.

Para René Passeron (2003), dois são os momentos distintos que instauram uma obra de arte: a arte do fazer/ poética, realizada pelo artista e, na continuidade, a arte do apreciar/ estética, realizada pelo espectador. Esta separação compreende uma questão de tempo e espaço cronológico, cada momento ocorrendo distintamente. O artista encontra-se na ponta de um procedimento linear que começa nele e acaba no espectador.

Mas, Umberto Eco no livro "Obra Aberta" (2005) pressupõe que o espectador participa efetivamente na instauração de uma obra de arte, ainda que se diga finalizada pelo artista, e mesmo naquele modelo tradicional. Esta ideia de abertura vem conferir ao espectador o estatuto de responsável por uma espécie de complementação mental do fazer do artista, o que de certa forma desmonta a linearidade proposta por Passeron, porém não no sentido prático de um fazer artesanal. Anterior a Eco, também Marcel Duchamp já reivindicava uma participação mental que autorizava o espectador a executar esta tarefa. É como se, antes desse contato, o artista não pudesse anunciar a conclusão de sua obra. Cabe salientar que há uma distinção entre a postura de Duchamp e a abordagem que se deseja neste artigo, diferença que se manifesta no aspecto cognitivo que as operações mentais revelam como "produção". Aqui, como já vimos, não operamos com esta lógica,

Não podemos esquecer que há práticas artísticas cujo plano de composição técnico (trabalho do material), propositalmente, nasce e se mantém aberto, pois o artista aguarda que o espectador, a seu modo e momento, produza sentido no tempo mesmo que transcorre a experiência. É o caso das instalações ${ }^{7}$, computacionais ou não, propostas identificadas como arte de

\footnotetext{
${ }^{7}$ As instalações são propostas que surgiram em meados do século XX por força dos processos de desmaterialização do objeto de arte e se encontram categorizadas dentro da Arte Conceitual.
} 
participação, "onde processos de manipulação e interação física com a obra acrescentam atos de liberdade sobre a mesma” (PLAZA, 2001). Essa não será apenas uma experiência mental, se quisermos seguir com Duchamp, ela estará em relação também a ações corporais sensoriais.

Destacamos as propostas dos artistas brasileiros Hélio Oiticica e seus "Parangolés" e Ligia Clark e seus "Bichos", obras que pedem ao público uma ação corporal, sensorial, tátil. Este tipo de obra identifica o então espectador como participador, outros termos como interagente, corpo-interator (COELHO, 2009, p. 227), também são empregados, dando a entender que há entre sujeito e objeto uma processualidade técnica, ou seja, o espectador se envolvendo fisicamente com o trabalho do artista na perspectiva de alcançar o plano estético (trabalho das sensações). Por força desta condição produtora de sentido, aproximam-se obra e sujeito; provoca-se um deslocamento das posições tão bem definidas pela poética e pela estética de Passeron.

A experiência com propostas de arte mediada pela computação, como a Web Arte, por exemplo, coloca o espectador frente a imagens digitais. Podemos falar em interatividade, abertura de terceiro grau (PLAZA, 2001), quando esta permite uma experiência utilizando mouse e teclado que dá ao interagente a possibilidade de realizar interferências, estas irão variar na medida em que variarem os dispositivos técnicos e o preparo da imagem, pelo artista.

Das práticas artísticas que oferecem experiências potentes podem nascer práticas pedagógicas de mesma intensidade, a promoverem o sentido como produção de atos de criação. Há muito de artista naquele professor que investe em processos de captação de forças do real, produzindo proposições, enunciando o possível dos acontecimentos aos quais foi lançado. Envolto com os signos de sua profissão, capturado por forças de sua matéria de trabalho, ele se vê impelido a criar situações de aprendizagem nas quais outras produções podem se tornar possíveis, lembrando-se do compartilhamento com o outro, sem amarras ou julgamentos de juízos.

Quando um professor toma a produção de sentido para tratar de experiência estética com imagens de arte, a partir de um referencial que estimula 
atos de criação, há uma aposta na crença de que o desconhecido, aquelas imagens que parecem inéditas às lembranças dos alunos, podem se tornar material de trabalho, desde o primeiro momento, quando não havia a mínima informação. Nessas condições o conhecer adquire traços de um processo de investigação que resulta de uma produção de saberes, mesmo quando ainda nada foi experimentado ou maquinado. Mesmo quando ainda não se entrou no regime das máquinas desejantes, segundo Deleuze e Guattari (1976), regimes que escapam da representação e da significação, uma maquinação produtora de quantidades intensivas que se passa entre os corpos, posicionada contra os automatismos e as banalizações. Produção de sentido como criação, potencialização, atualização de virtualidades. Desterritorializações. Corrente de fluxos, forças incorporais e invisíveis. Resultados não passíveis de descrição, como se fossem elementos de uma lista de ocorrências.

Nesse contexto, o funcionamento da produção de sentido de um aluno, é uma experiência que escapa às aparências, ao que estaria evidente na relação sujeito e objeto. Refiro-me ao fato do empenho não se reduzir a uma decifração da obra, a uma decodificação pela linguagem - acertar os motivos da criação ou adivinhar o contexto onde ela foi gerada. Se o sentido é a proposição que expressa um acontecimento, um acontecimento não tem fronteiras, limites, tudo nele cabe.

Para os Estoicos, a partir de outro modo de "pensar", as ideias são efeitos dos encontros que se dão entre os corpos, daí a mistura de corpos, e não a origem de tudo que há no mundo sensível, modo bem distinto de Platão. Ideias são construídas, inventadas, maquinadas pelos corpos em envolvimento e afecção. Ou seja, o sentido está menos para uma confirmação de dados (ideias pré-concebidas) do que para uma invenção de mundos a partir e com os dados.

É, pois agradável que ressoe hoje a boa nova: o sentido não é nunca princípio ou origem, ele é produzido. Ele não é algo a ser descoberto. Restaurado ou reempregado, mas algo a produzir por meio de novas maquinações. (DELEUZE, 1998b, p. 75).

Na perspectiva deleuzeana, apoiada nos Estoicos, não há um sentido transcendente nas coisas; a lógica do sentido é perceber que há multiplicidades 
a se produzir na instabilidade do mundo sensível, imanente, tudo uma questão de devir. Puro fluxo. O "puro devir, o ilimitado, é a matéria do simulacro na medida em que se furta à ação da ideia, na medida em que contesta tanto o modelo como a cópia". (DELEUZE, 1998b, p. 02). As ideias insistem ou persistem. O ilimitado, matéria do simulacro, não se submete à ação da ideia, ele rejeita o modelo, e não quer ser cópia.

A experiência do sentido como produção de atos de criação, coloca artista e espectador, professor de arte e aluno, como corpos orgânicos que se tornam outros. Segundo Sueli Rolnik um corpo orgânico que não se encerra em sua constituição fisiológica mostra-se como um corpo-força. Enquanto sistema nervoso, acentrado, tal corpo está destituído de uma organização fixa, mental, e constitui-se como um corpo intensivo aberto aos encontros. Este corpo, Rolnik denomina de corpo vibrátil (2007, p. 2), avaliado a partir da ideia de vibração, e em mistura com outros corpos, ele é um híbrido de vida e arte, produzindo sentido para a experiência na expressão de proposições. Produção em rizomas (DELEUZE; GUATTARI, 1996), o sentido, vale repetir, quarta dimensão da proposição junto com a designação, a manifestação e a significação, não segue uma linha hierarquia de subordinações, sendo as conexões, os saltos, os cruzamentos, os princípios de seu funcionamento. Para o sentido não há estrutura prévia, nem modelos de significações, só um grande território de possibilidades.

Portanto, a produção de sentido do ponto de vista do corpo vibrátil, vale reforçar, não tem relação com decifrar enigmas, como se esses fossem revelados como essências ou interioridades. Nada relacionado com processos de adivinhações, quando só está valendo a resposta que melhor atende à surrada pergunta "o que o artista quis dizer com isso?". Nada a ver com o bom senso (sentido correto) ou com o senso comum (identidade fixa). Muito mais associado a paradoxos. Para Deleuze, o "paradoxo é, em primeiro lugar, o que destrói o bom senso como sentido único, mas, em seguida, o que destrói o senso comum como designação de identidades fixas" (1998b, p. 03). O paradoxo, enquanto transforma o que é permanente em puro devir, funciona como um dispositivo desautomatizador da percepção do mundo. Sentido: nada a ser 
buscado, tudo a ser produzido, na destituição da identidade de um Eu, como ocorre com a personagem Alice, que "não cresce sem ficar menor e inversamente" (DELEUZE, 1998b, p. 01).

A produção de sentido torna visível outra multiplicidade, "que não tem necessidade alguma da unidade para formar um sistema" (DELEUZE, 1988, p. 236). Como assinala Deleuze, trata-se de pensar a multiplicidade em si e por si. Este pensar implica em não se separar do sentido, ele se produz exatamente na articulação intrínseca do múltiplo, na relação da multiplicidade com ela mesma. Não se trata de uma multiplicidade fornecida pelo número de elementos que contém, "uma multiplicidade para cada coisa, um mundo de fragmentos nãototalizáveis comunicando-se através de relações exteriores" (ALLIEZ, 1996, p.19). A multiplicidade entendida valoriza a multiplicidade de vozes e se contrapõe a ideia de um sujeito fixo, conformado por um eu e uma consciência irredutíveis, como uma "forma originária evoluindo no mundo como em um cenário exterior ou um conjunto de dados aos quais ele se contentaria em reagir" (ZOURABICHVILI, 2004, p. 21). Ao contrário, um sujeito fixo pode se tornar criador ao se constituir em agenciamentos, acoplamentos entre regimes de signos e conjuntos de relações materiais. Assim, uma existência dependerá de como um sujeito é tomado em agenciamentos, ou seja, levado pelas circunstâncias dos encontros.

Contrariando Platão e a forma de acesso ao mundo inteligível (atemporal e indestrutível), que se dá pela experiência do mundo sensível, na tentativa de encontrar o lugar onde se fundamenta o conhecer, ou seja, a alma; contrariando a máxima protagoriana - o homem é a medida de todas as coisas -, outro modo de conhecimento foi defendido e apresentado neste artigo. Esse modo de gerar conhecimento - e conhecimento se confunde com sentido, segue um caminho conceitual no qual interessa saber como se produz um sentido, mas sem julgar o sentido de um acontecimento. Fica a questão: e como esta teorização se comporta na prática interativa com imagens? O que se oporia a uma "lista de ocorrências"? Abordar perguntas que indagam sobre o que dispara uma produção de sentido quando se trata de obra de arte visual, em como esta 
experiência segue os conceitos trabalhados aqui, fica como promessa para uma continuação em uma próxima escrita.

\section{Referências}

ALLIEZ, Eric. Deleuze filosofia virtual. São Paulo: Ed. 34, 1996.

AUMONT, Jacques. A imagem. Campinas: Papirus, 2012.

COELHO, Alberto. Instalações interativa computacionais: exercícios de contemplação interfaceada de sensações, 2009. 265f. Tese (doutorado) - Programa de Pós-Graduação em Artes Visuais, Universidade Federal do Rio Grande do Sul, Porto Alegre, 2009. Disponível em: <http://hdl.handle.net/10183/28006>. Acesso em 02 fev. 2010.

DELEUZE, Gilles. O que é a filosofia? São Paulo: Ed. 34, 1992.

DELEUZE, Gilles. Diálogos. São Paulo: Escuta, 1998a.

DELEUZE, Gilles. Lógica do sentido. São Paulo: Editora Perspectiva, 1998b.

DELEUZE, Gilles. Diferença e repetição. Rio de Janeiro: Graal, 2006.

DELEUZE, Gilles; GUATTARI, Felix. O anti-Édipo. Rio de Janeiro: Imago, 1976.

DELEUZE, Gilles; GUATTARI, Felix. Mil platôs: capitalismo e esquizofrenia, v.4. Rio de janeiro: Ed. 34, 1996.

ECO, Humberto. Obra aberta: forma e indeterminação nas poéticas contemporâneas. São Paulo: Perspectiva, 2005.

PASSERON, René. Da estética à poiética. Porto Arte, Porto Alegre, v. 8, n. 15, p. 103-116, 1997.

PIZARRO, Angelica de P. Acontecimento: um incorporal estóico na filosofia de Deleuze. Disponível em: <https://www.academia.edu/4199705/A_ideia_de_Incorporais_Deleuze_ estoicos>. Acesso em 11 jun. 2015

PLAZA, Julio. Arte e interatividade: autor-obra-recepção. Disponível em: <http://www2.eca.usp.br/ cap/ars2/arteeinteratividade.pdf>. Acesso em 20 abr. 2001.

ROLNIK, Suely. "Fale com ele" ou como tratar o corpo vibrátil em coma. Disponível em: <http://www.pucsp.br/nucleodesubjetividade/Textos/SUELY/falecomele.pdf>. Acesso em 07 mai. 2007.

ROLNIK, Suely. Por um estado de arte a atualidade de Lygia Clark. Disponível em: <http://www. pucsp.br/nucleodesubjetividade/Textos/SUELY/estadodearte.pdf>.Acesso em 02 ago. 2008.

SAMAN, Ethiene (Org.). Como pensam as imagens. Campinas: Editora da Unicamp, 2012.

SPINOZA, Benedictus de. Ética. Belo Horizonte: Autêntica, 2009.

ZOURABICHVILI, François. O vocabulário de Deleuze. Rio de Janeiro: Relume Dumará, 2004.

\section{Alberto d'Avila Coelho}

Pós-doutorando na Faculdade de Educação da Universidade Federal do Rio Grande do Sul. Doutor em Artes Visuais, pela UFRGS, com estudos desenvolvidos na Universidade Politécnica de Valencia, Espanha. Mestre em Artes Visuais, pela UFRGS. Graduado em Licenciatura, Educação Artística - habilitação Artes Plásticas pela Universidade Federal de Pelotas. Professor efetivo do Instituto Federal de Educação, Ciência e Tecnologia Sul-rio-grandense, campus Pelotas/RS. Membro do grupo interinstitucional de pesquisa Educação e Contemporaneidade: experimentações com arte e filosofia - EXPERIMENTA. Área de pesquisa Educação, ênfase em formação docente e ensino de arte, atendendo problemáticas que envolvem a experiência estética, o corpo, a subjetividade digital e a arte contemporânea.

E-mail: albercoelho@terra.com.br

Currículo: http://lattes.cnpq.br/9433033352601912 